\title{
US-China Clean Energy Research Center on Building Energy Efficiency: Materials that Improve the Cost-Effectiveness of Air Barrier Systems
}

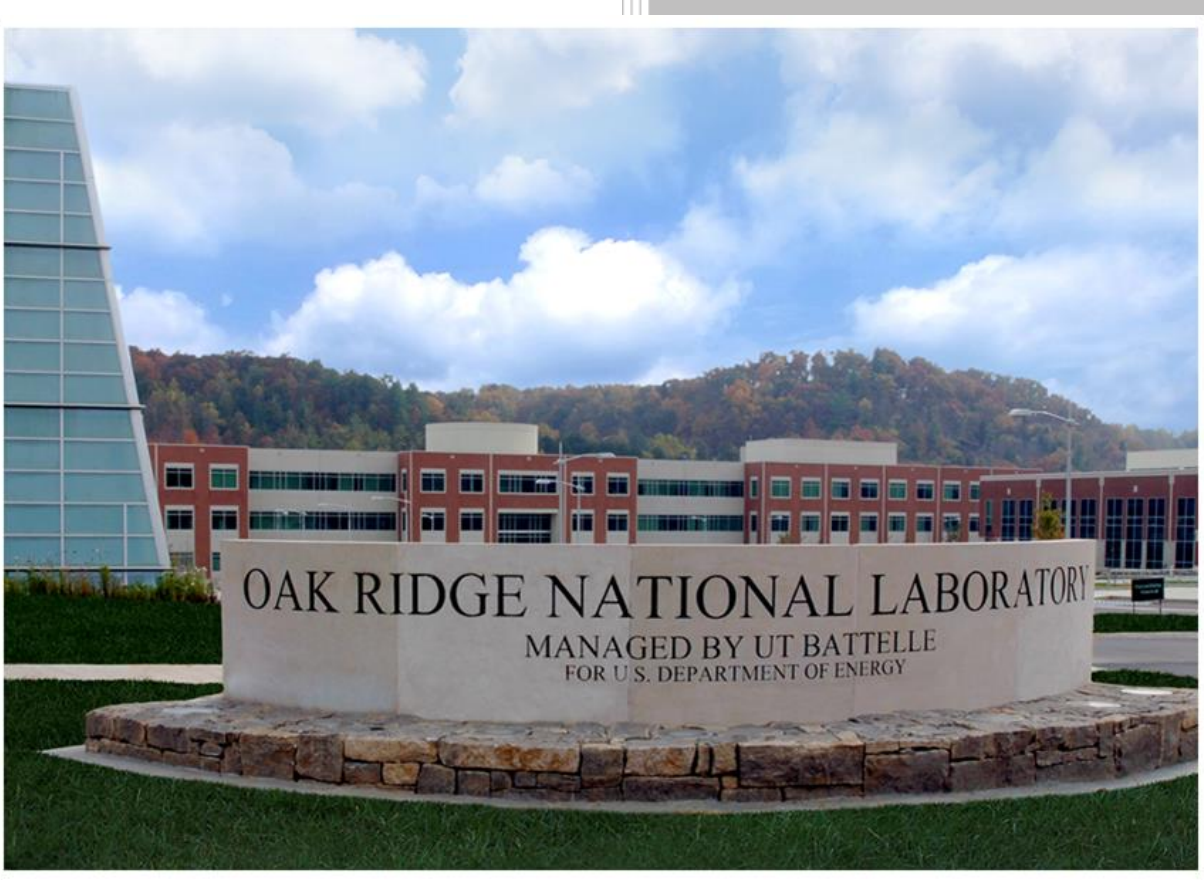

Diana E. Hun

December 2016 


\title{
DOCUMENT AVAILABILITY
}

Reports produced after January 1, 1996, are generally available free via US Department of Energy (DOE) SciTech Connect.

Website http://www.osti.gov/scitech/

Reports produced before January 1, 1996, may be purchased by members of the public from the following source:

\author{
National Technical Information Service \\ 5285 Port Royal Road \\ Springfield, VA 22161 \\ Telephone 703-605-6000 (1-800-553-6847) \\ TDD 703-487-4639 \\ Fax 703-605-6900 \\ E-mail info@ntis.gov \\ Website http://www.ntis.gov/help/ordermethods.aspx
}

Reports are available to DOE employees, DOE contractors, Energy Technology Data Exchange representatives, and International Nuclear Information System representatives from the following source:

Office of Scientific and Technical Information

PO Box 62

Oak Ridge, TN 37831

Telephone 865-576-8401

Fax 865-576-5728

E-mail reports@osti.gov

Website http://www.osti.gov/contact.html

This report was prepared as an account of work sponsored by an agency of the United States Government. Neither the United States Government nor any agency thereof, nor any of their employees, makes any warranty, express or implied, or assumes any legal liability or responsibility for the accuracy, completeness, or usefulness of any information, apparatus, product, or process disclosed, or represents that its use would not infringe privately owned rights. Reference herein to any specific commercial product, process, or service by trade name, trademark, manufacturer, or otherwise, does not necessarily constitute or imply its endorsement, recommendation, or favoring by the United States Government or any agency thereof. The views and opinions of authors expressed herein do not necessarily state or reflect those of the United States Government or any agency thereof. 
Energy and Transportation Science Division

\section{US-CHINA CLEAN ENERGY RESEARCH CENTER ON BUILDING ENERGY EFFICIENCY: \\ MATERIALS THAT IMPROVE THE COST-EFFECTIVENESS OF AIR BARRIER SYSTEMS}

Diana E. Hun

Date Published: December 2016

Prepared by

OAK RIDGE NATIONAL LABORATORY

Oak Ridge, TN 37831-6283

managed by

UT-BATTELLE, LLC

for the

US DEPARTMENT OF ENERGY

under contract DE-AC05-00OR22725 



\section{TABLE OF CONTENTS}

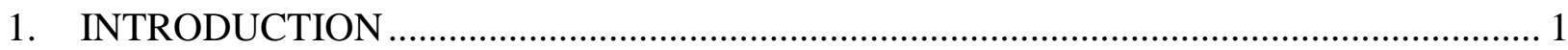

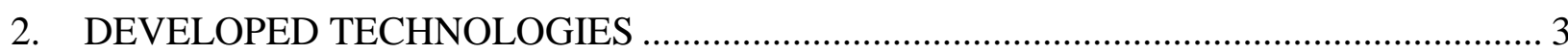

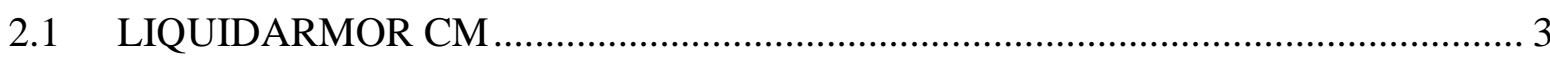

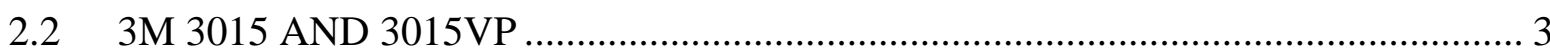

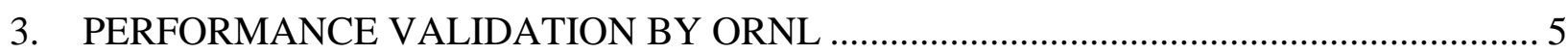

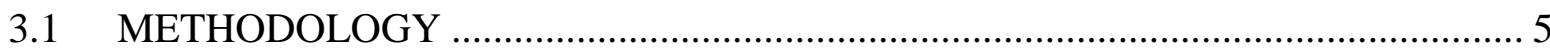

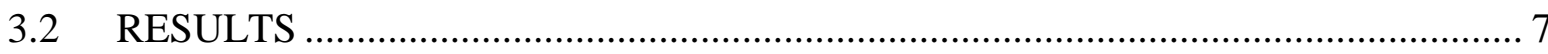

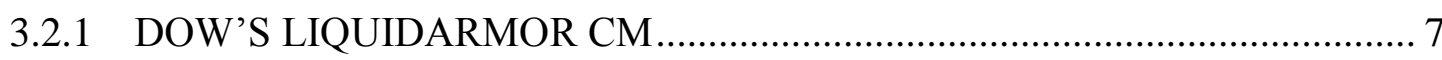

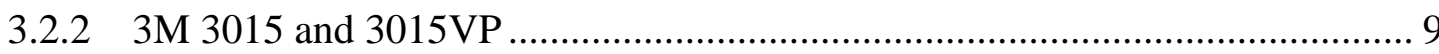

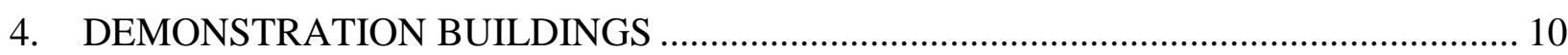

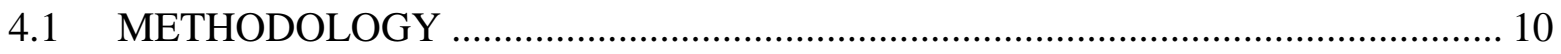

4.2 PURSUED SITES AND RESULTS ................................................................. 11

4.2.1 China Academy of Building Research, Beijing ................................................ 11

4.2.2 Singyes Solar, Zhuhai ………………………….................................. 12

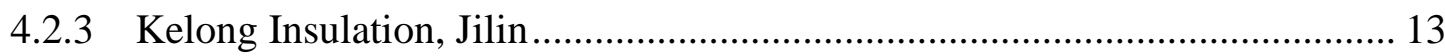

4.2.4 Rixin Technologies, Wuhan..................................................................... 13

4.2.5 P+ Demonstration Building, Wujin ............................................................. 14

4.2.6 Shanghai Municipal State-Owned Assets Supervision and Administration Commission ........................................................................................ 14

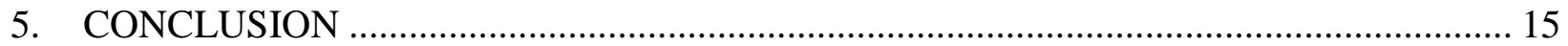




\section{ACKNOWLEDGEMENTS}

This work was supported by the Assistant Secretary for Energy Efficiency and Renewable Energy, Office of the Building Technology Program, U.S. Department of Energy, under Contract No. DE- AC05$00 \mathrm{OR} 22725$. 


\section{INTRODUCTION}

The US-China Clean Energy Research Center (CERC) was launched in 2009 by US Energy Secretary Steven Chu, Chinese Minister of Science and Technology Wan Gang, and Chinese National Energy Agency Administrator Zhang Guobao. This 5-year collaboration emerged from the fact that the United States and China are the world's largest energy producers, energy consumers, and greenhouse gas emitters, and that their joint effort could have significant positive repercussions worldwide. CERC's main goal is to develop and deploy clean energy technologies that will help both countries meet energy and climate challenges. Three consortia were established to address the most pressing energy-related research areas: Advanced Coal Technology, Clean Vehicles, and Building Energy Efficiency (BEE). The project discussed in this report was part of the CERC-BEE consortia; its objective was to lower energy use in buildings by developing and evaluating technologies that improve the cost-effectiveness of air barrier systems for building envelopes.

Reducing air leakage is among the most cost-effective strategies for reducing energy loads from building envelopes (Figure 1). Although air barrier materials are readily available to reduce infiltration rates, the quality of the workmanship during their installation can significantly influence the performance of the air barrier system. Consequently, Oak Ridge National Laboratory (ORNL) partnered with Dow Chemical Company (Dow) and 3M to develop and validate the performance of air barrier materials and components that improve the cost-effectiveness of these systems. More specifically, when compared with readily available products, the newly developed technologies would have the following attributes:

- Lower level of skills required for proper installation

- Easier and faster installation

- Comparable installed cost to available technologies

- Equal or better performance

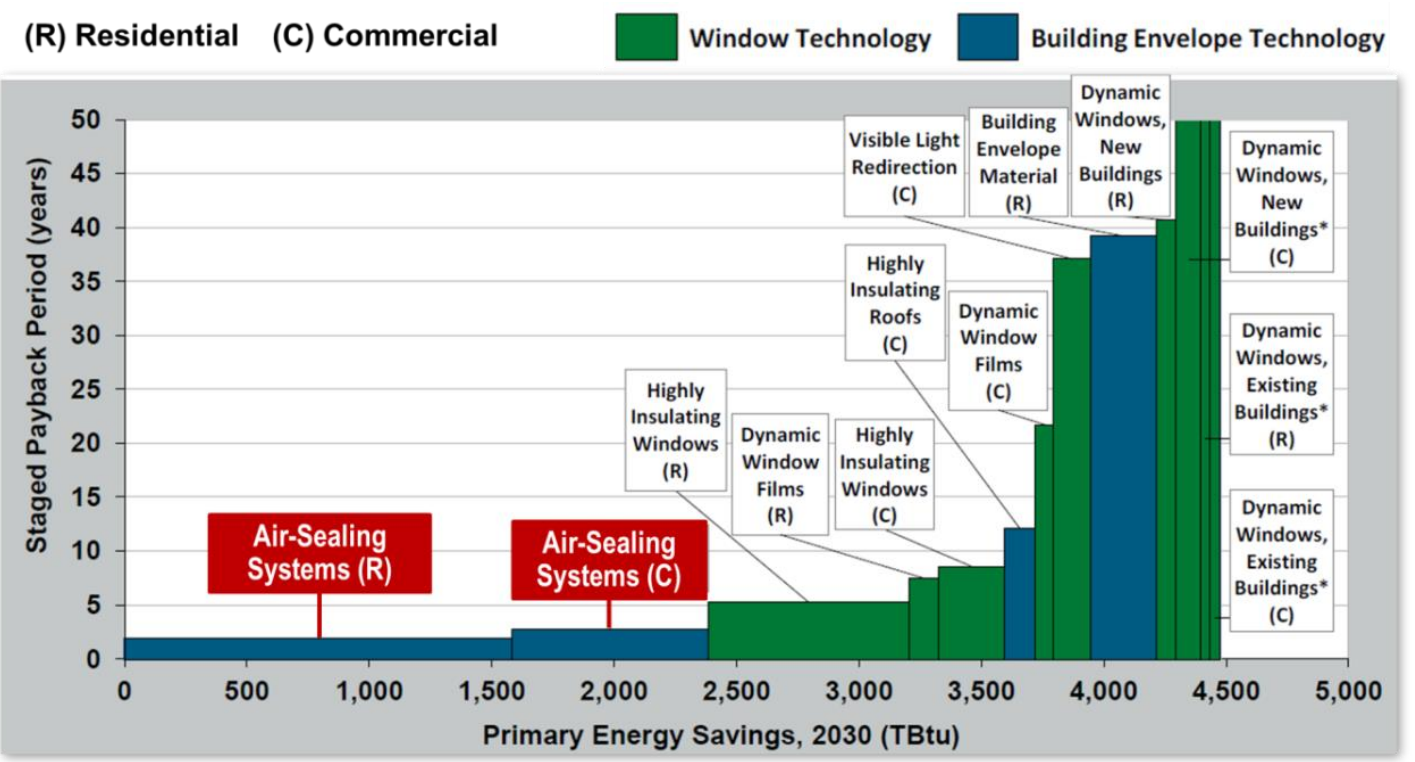

Figure 1. Cost analyses of envelope technologies for residential and commercial buildings. Results indicate the airsealing systems have the largest energy savings and lowest staged payback period. (DOE 2014, Windows and Building Envelopes Research and Development: Roadmap for Emerging Technologies) 
To achieve these goals, Dow focused on developing a spray-applied liquid flashing that can span gaps of up to $1 / 4$ in. in width without a supporting material. It would represent a significant improvement over tapes, which are difficult to properly install over angular and curved areas (Figure 2A), and over other liquid flashings that need to be combined with backer rods and/or transition membranes (Figure 2B). 3M's aimed its efforts at developing self-adhered membranes that can be installed over most construction materials without a primer, because primers require installation and curing time (Figure 3A), and inadequate priming can lead to detachment of the membrane (Figure 3B).
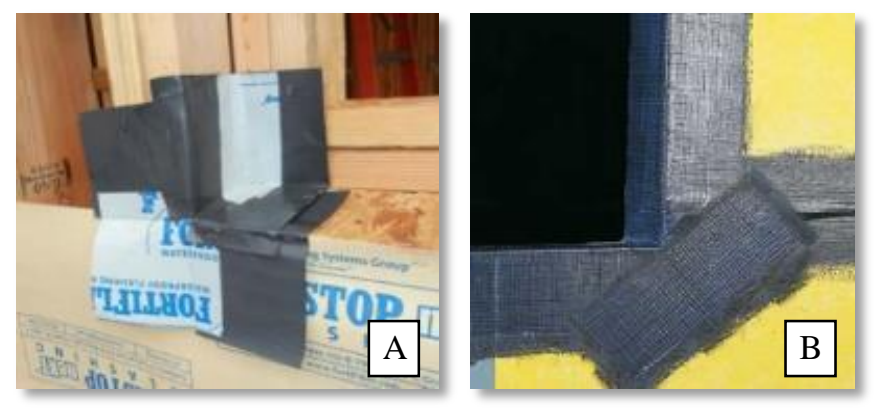

Figure 2. Most flashing technologies require several installation steps and/or materials, whereas LIQUIDARMOR is a single-step and single-component flashing. (A) Shiplap layers of tape are required to flash the corners of window rough openings. (B) A transition membrane is needed before the installation of some liquid flashings.
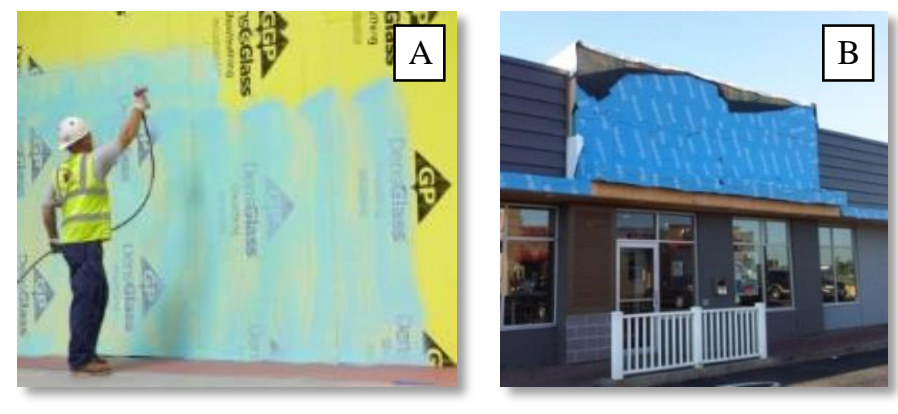

Figure 3. (A) Asphalt-based membranes require that substrates be primed for membrane adherence. (B) Inadequate priming can lead to the failure of the membrane.

The following were the objectives of the present project:

1. Dow would develop a spray-applied liquid flashing that could span gaps of up to $1 / 4 \mathrm{in}$. and could be installed with a regular airless sprayer, roller, or brush.

2. 3M would develop a self-adhered membrane that would serve as an air and water barrier.

3. ORNL would develop a test protocol to validate the performance of the Dow and $3 \mathrm{M}$ technologies through laboratory experiments.

4. ORNL would validate the performance of the Dow and $3 \mathrm{M}$ technologies through the developed test protocol.

5. ORNL, Dow, and 3M would demonstrate the new technologies and/or quantify improvements over existing products in buildings in China.

ORNL and Dow started working on these goals in 2013, and 3M joined the team in 2014. This project was completed in the spring of 2016. 


\section{DEVELOPED TECHNOLOGIES}

\subsection{LIQUIDARMOR CM}

Dow used its in-house facilities and hired private laboratories to conduct primarily small-scale laboratory tests throughout the development of the spray-applied liquid flashing. These tests included

- ASTM D412-15a, Standard Test Method for Vulcanized Rubber and Thermoplastic Elastomers: Tensile strength and elongation at break

- ASTM D903-98(2010), Standard Test Method for Peel or Stripping Strength of Adhesive Bonds

- ASTM D1970/D1970M-15a, Standard Test Method for Self-Adhering Polymer Modified Bituminous Sheet Materials Used as Steep Roofing Underlayment for Ice Dam Protection

- ASTM E96/E96M-16, Standard Test Method for Water Vapor Transmission of Materials

- ASTM E2178-13, Standard Test Method for Air Permeance of Building Materials

- AATCC 127, Water Resistance: Hydrostatic Pressure Test

In November 2014, Dow launched residential and commercial versions of its liquid flashing as LIQUIDARMOR RS and LIQUIDARMOR CM, respectively, and received a patent on this product (US 8641846 B2). To date, LIQUIDARMOR is the only spray-applied flashing in the market that can span gaps of up to a $1 / 4$ in. in width without a supporting material (Figure 4). Initial field trials indicated that LIQUIDARMOR is up to four times faster to install than tape. In 2015, LIQUIDARMOR was an R\&D 100 finalist; and in 2016, Dow Chemical Company won the Gold Edison Award for Building Construction and Lighting Innovations. In both cases, ORNL contributed to the development of the product with simulations that estimated potential energy savings due to the improvements in airtightness.
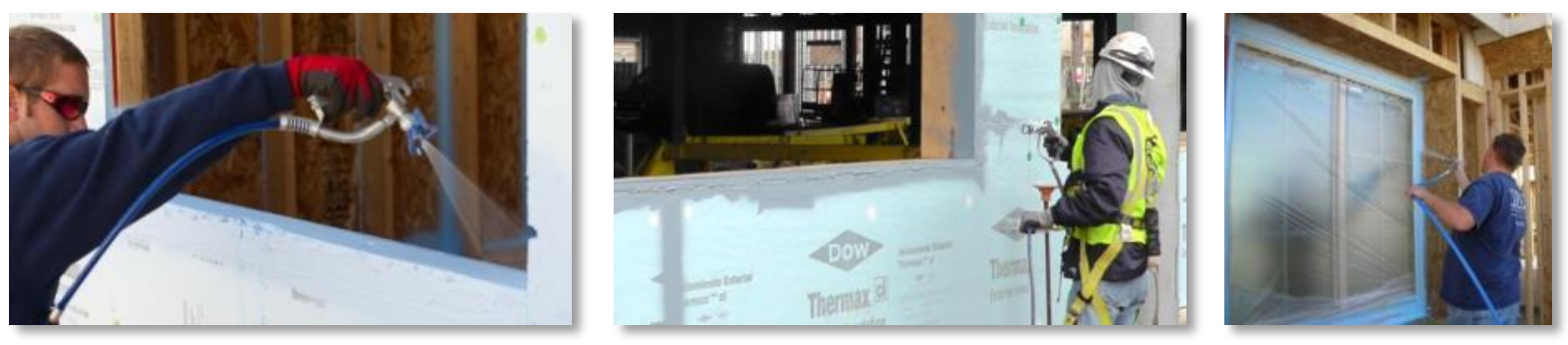

Figure 4. LIQUIDARMOR RS and LIQUIDARMOR CM can be installed with an airless sprayer, roller, or brush over gaps of to $1 / 4$ in. without a supporting material, which significantly decreases the amount of detailing time.

\subsection{M 3015 AND 3015VP}

$3 \mathrm{M}$ used its in-house facilities and hired private laboratories to perform primarily small-scale laboratory tests while it developed its primer-less, self-adhered membranes. These tests included

- ASTM D882-12, Standard Test Method for Tensile Properties of Thin Plastic Sheeting

- ASTM D1970/D1970M-15a, Standard Test Method for Self-Adhering Polymer Modified Bituminous Sheet Materials Used as Steep Roofing Underlayment for Ice Dam Protection

- ASTM D3330/D3330M, Standard Test Method for Peel Adhesion of Pressure-Sensitive Tape

- ASTM D3652/D3652M-01(2012), Standard Test Method for Thickness of Pressure-Sensitive Tapes 
- ASTM D4541-09e1, Standard Test Method for Pull-Off Strength of Coatings using Portable Adhesion Testers

- ASTM E96/E96M-16, Standard Test Method for Water Vapor Transmission of Materials

- ASTM E2178-13, Standard Test Method for Air Permeance of Building Materials

- AATCC 127, Water Resistance: Hydrostatic Pressure Test

The 3M Air and Vapor Barrier 3015 (Figure 5) was introduced to the United States in 2013 as a selfadhered membrane that can be applied to most construction materials-including exterior-grade fiberglass mat gypsum sheathings and concrete masonry units-without a primer. In the spring of 2016, $3 \mathrm{M}$ launched 3015VP, the vapor-permeable version of this membrane (Figure 6). A key feature of 3015 and $3015 \mathrm{VP}$ is that they can be installed at $0^{\circ} \mathrm{F}$. In contrast, membranes with asphalt-based adhesives typically cannot be used below $40^{\circ} \mathrm{F}$ because they become stiff.
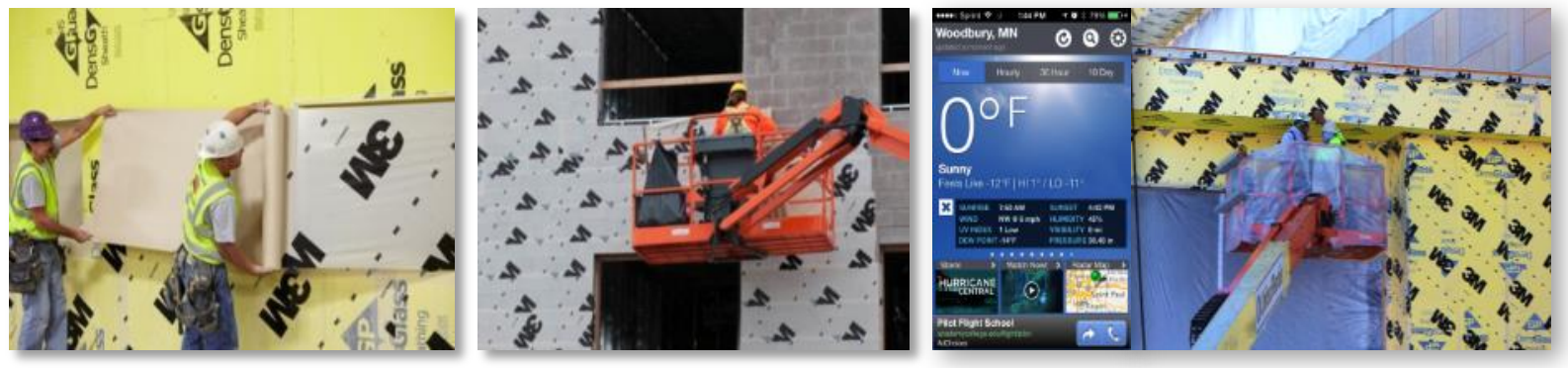

Figure 5. 3M air and vapor barrier 3015 can be installed over most building materials without a primer when ambient temperatures are as low as $0^{\circ} \mathrm{F}$.

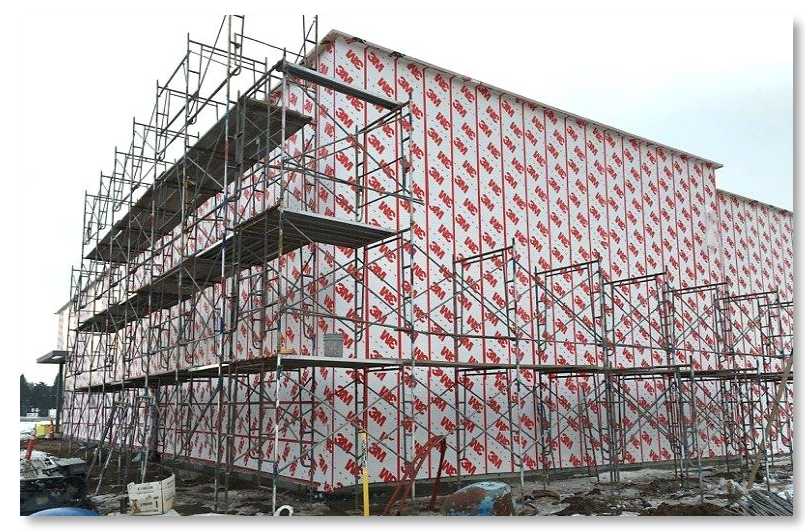

Figure 6. 3M vapor-permeable air barrier 3015VP can be installed over most building materials without a primer when ambient temperatures are as low as $0^{\circ} \mathrm{F}$. The photograph shows a project on which $3015 \mathrm{VP}$ was installed at $23^{\circ} \mathrm{F}$. 


\section{PERFORMANCE VALIDATION BY ORNL}

\subsection{METHODOLOGY}

ORNL conducted a review of available test standards to determine how the construction industry has agreed to age air and water barriers, and to evaluate the air and water penetration of large-scale wall assemblies. ORNL combined these tests into a single procedure that would age the wall with pressure and temperature cycles and would examine the air and water penetration of a test wall before and after aging. Combining these tests subjects the wall to a more stringent evaluation than that currently followed by the air barrier industry, while following procedures that have been accepted by manufacturers. Figure 7 lists the sequence of the selected tests and the criteria for passing them. The tests and their implementation sequence are

- ASTM E283-04 (2012), Standard Test Method for Determining Rate of Air Leakage Through Exterior Windows, Curtain Walls, and Doors Under Specified Pressure Differences Across the Specimen. It measures air leakage at specified pressure differentials to determine the airflow equation and leakage rate at $1.57 \mathrm{psf}$.

- ASTM E331-00 (2009), Standard Test Method for Water Penetration of Exterior Windows, Skylights, Doors, and Curtain Walls by Uniform Static Air Pressure Difference. The test wall is simultaneously sprayed with water at a minimum rate of $5.0 \mathrm{US}$ gal $/ \mathrm{ft}^{2} \cdot \mathrm{h}$ and subjected to a constant pressure of 2.86 psf for 15 minutes.

- ASTM E1424-91 (2008), Standard Test Method for Determining Rate of Air Leakage Through Exterior Windows, Curtain Walls, and Doors Under Specified Pressure and Temperature Differences Across the Specimen. The wall is conditioned at $110^{\circ} \mathrm{F}$ and $0^{\circ} \mathrm{F}$ to determine how the expansion and contraction of materials affect air leakage.

- ASTM E2357-11, Standard Test Method for Determining Air Leakage or Air Barrier Assemblies. The wall is aged through sustained and cyclic pressure loads. The sustained loads are +8.4 and -8.4 psf, and each lasts an hour. These are followed by 4,000 pressure cycles ranging from 0 to $16.7 \mathrm{psf}$ and 4,000 cycles ranging from 0 to $-16.7 \mathrm{psf}$.

- AAMA 501.5-07, Test Method for Thermal Cycling of Exterior Walls. The test wall is subjected to three temperature cycles that range from 0 to $150^{\circ} \mathrm{F}$. Minimum and maximum temperatures are maintained for 2 hours in each cycle.

- ASTM E2268-04 (2011), Standard Test Method for Water Penetration of Exterior Windows, Skylights, and Doors by Rapid Pulsed Air Pressure Difference. The test wall is simultaneously sprayed with water at a minimum rate of $5.0 \mathrm{US} \mathrm{gal} / \mathrm{ft}^{2} \cdot \mathrm{h}$ and subjected to pressure cycles that range from 1.46 to $4.39 \mathrm{psf} \mathrm{Pa}$ for at least 10 minutes. 


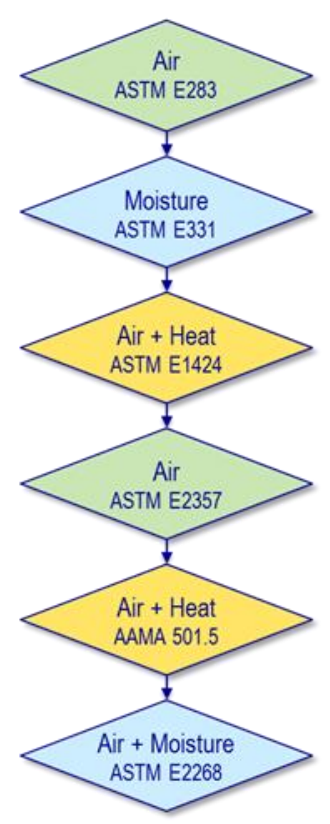

Pass Criteria

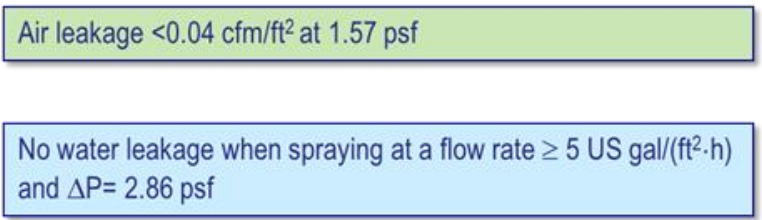

Air leakage $<0.04 \mathrm{cfm} / \mathrm{ft}^{2}$ at $1.57 \mathrm{psf}$ at

Warm conditions: $T_{\text {in }}=72^{\circ} \mathrm{F} \quad \mathrm{T}_{\text {out }}=110^{\circ} \mathrm{F}$

Cold conditions: $\quad \mathrm{T}_{\text {in }}=72^{\circ} \mathrm{F} \quad \mathrm{T}_{\text {out }}=0^{\circ} \mathrm{F}$

Air leakage $<0.04 \mathrm{cfm} / \mathrm{ft}^{2}$ at $1.57 \mathrm{psf}$ after aging through

pressure cycles that simulate 15 -year wind loads

Air leakage $<0.04 \mathrm{cfm} / \mathrm{ft}^{2}$ at $1.57 \mathrm{psf}$ after aging through

temperature cycles ranging between $150^{\circ} \mathrm{F}$ and $0^{\circ} \mathrm{F}$

No water leakage when spraying at a flow rate $\geq 5 \mathrm{US} \mathrm{gal} /\left(\mathrm{ft}^{2} \cdot \mathrm{h}\right)$ and pressure cycles between 1.46 and 4.39 psf

Figure 7. Test protocol followed by ORNL to validate the performance of the Dow and 3M air barrier technologies.

In 2013, ORNL wrote the LabView code to conduct the aforementioned tests in its heat, air and moisture penetration chamber (Figure 8), calibrated the chamber according to the test standards, and performed several tryouts. In 2014 and 2015, ORNL built 8 by $10 \mathrm{ft}$ test walls that mostly followed the layout specified in the ASTM E2357 test standard, which includes vertical and horizontal joints in the exterior sheathing, a rectangular and an hexagonal electrical outlet, a 4 by 4 in. steel duct, a 1.5 in. diameter PVC pipe, and a 2 by $4 \mathrm{ft}$ plywood window (Figure 9). Gaps around penetrations were between $1 / 4$ and $3 / 8$ in. wide everywhere except around the window, where they were $1 / 2$ in. wide. The test wall frames consisted of $3 \% / 8$ by $15 / 8$ in., 18 gage steel studs. Dow and $3 \mathrm{M}$ selected the sheathing in the test walls, and ORNL coordinated with these manufacturers' potential changes to the material layout based on their research interests.

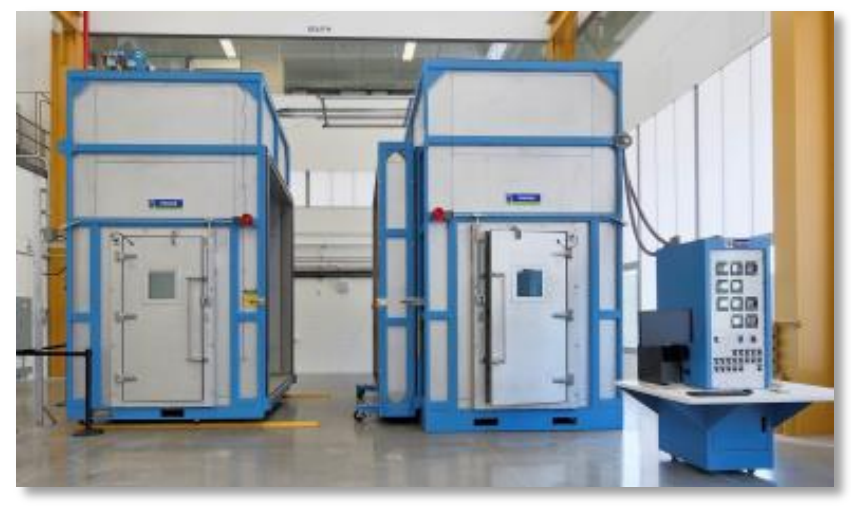

Figure 8. Heat, air, and moisture penetration (HAM) chamber. After a test wall is fixed between an indoor (left) and outdoor (right) room, it can be exposed to controlled temperatures, relative humidity values, static and dynamic pressures, sprayed water, and infrared radiation. Moreover, the HAM chamber is capable of measuring the flow rate of air that leaks through a test wall. 


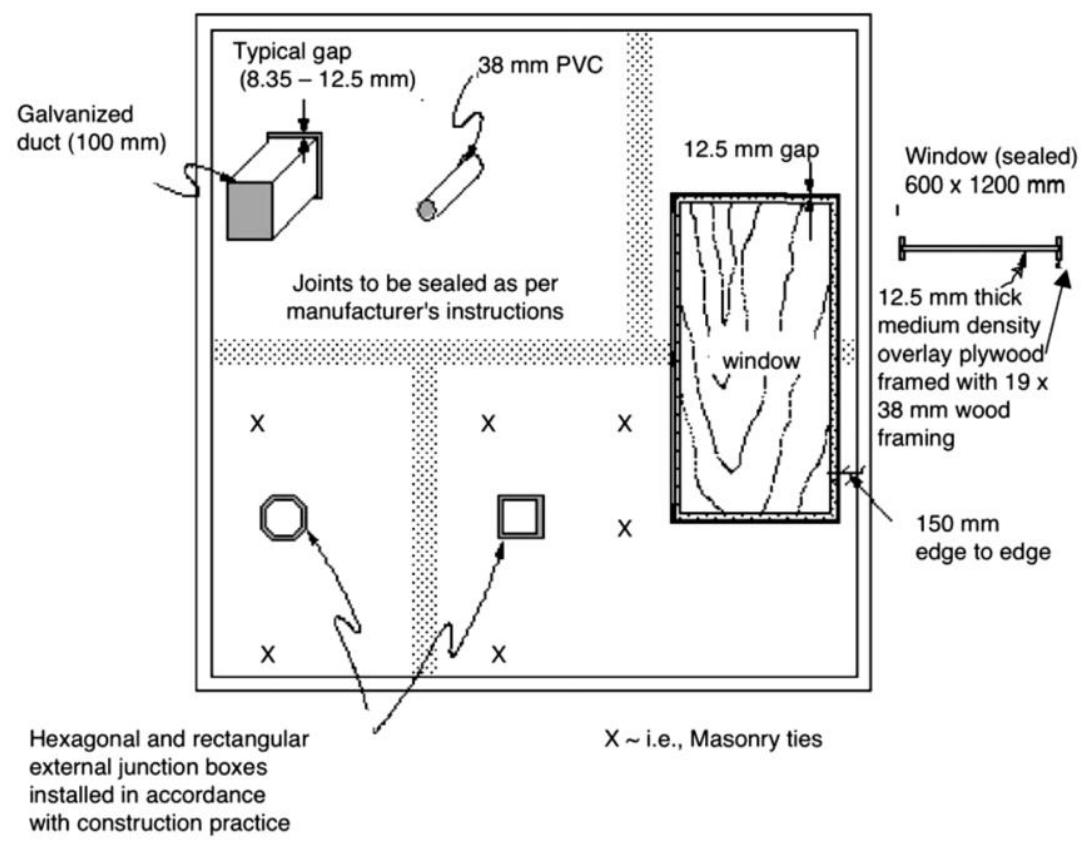

Figure 9. Wall assembly built according to ASTM E2357 test standard. ORNL mostly followed this material layout.

\subsection{RESULTS}

\subsubsection{DOW'S LIQUIDARMOR CM}

Four test walls were constructed. LIQUIDARMOR CM was installed either with a brush or a roller, and the applied thicknesses used were according to Dow's instructions. In the first test wall, $5 / 8$ in. thick THERMAX (ci) Exterior Insulation boards, which are foil-faced polyisocyanurate boards, were used as the exterior sheathing. LIQUIDARMOR CM was applied directly over gaps less than $1 / 4 \mathrm{in}$. wide between boards. Gaps around penetrations were wider than $1 / 4$ in.; therefore, these were first filled with onecomponent spray foam and afterward covered with LIQUIDARMOR CM (Figure 10).
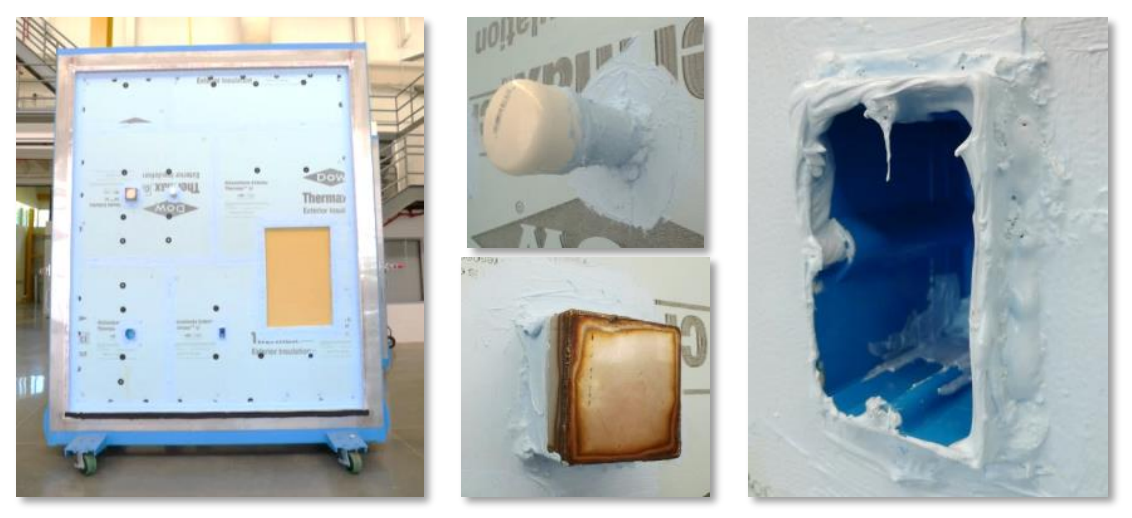

Figure 10. Test wall with $5 / 8$ in. thick THERMAX (ci) as the exterior sheathing. LIQUIDARMOR CM was used to seal the gaps between boards and around penetrations.

DensGlass, which is an exterior-grade fiberglass mat gypsum sheathing, was used as the exterior sheathing in the second test wall. The steps followed to install LIQUIDARMOR CM over gaps were the 
same as on the first wall. However, after all the gaps were sealed, LIQUIDARMOR CM was rolled over the entire surface area of the DensGlass boards so it would act as both the air and water barrier (Figure $11)$.
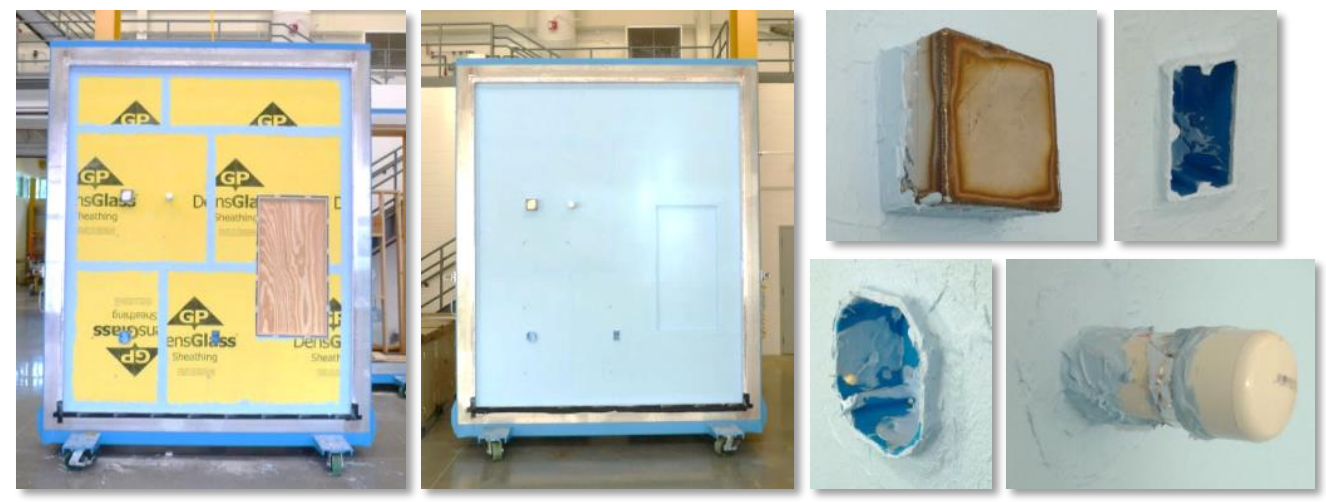

Figure 11. Test wall with $5 / 8$ in. thick DensGlass as the exterior sheathing. LIQUIDARMOR CM was used to seal all the gaps, as well as the air and water barrier

The third test wall was used to investigate the performance of LIQUIDARMOR CM over $1 / 4 \mathrm{in}$. wide gaps without a supporting material. Both $5 / 8$ in. thick THERMAX (ci) and $5 / 8$ in. thick DensGlass were used in the wall, and each included two 1/1/2 in. diameter PVC pipes (Figure 12), two rectangular electrical outlets, two hexagonal electrical outlets, and one 4 by 4 in. steel duct. Gaps around all of these penetrations were about $1 / 4$ in. wide.
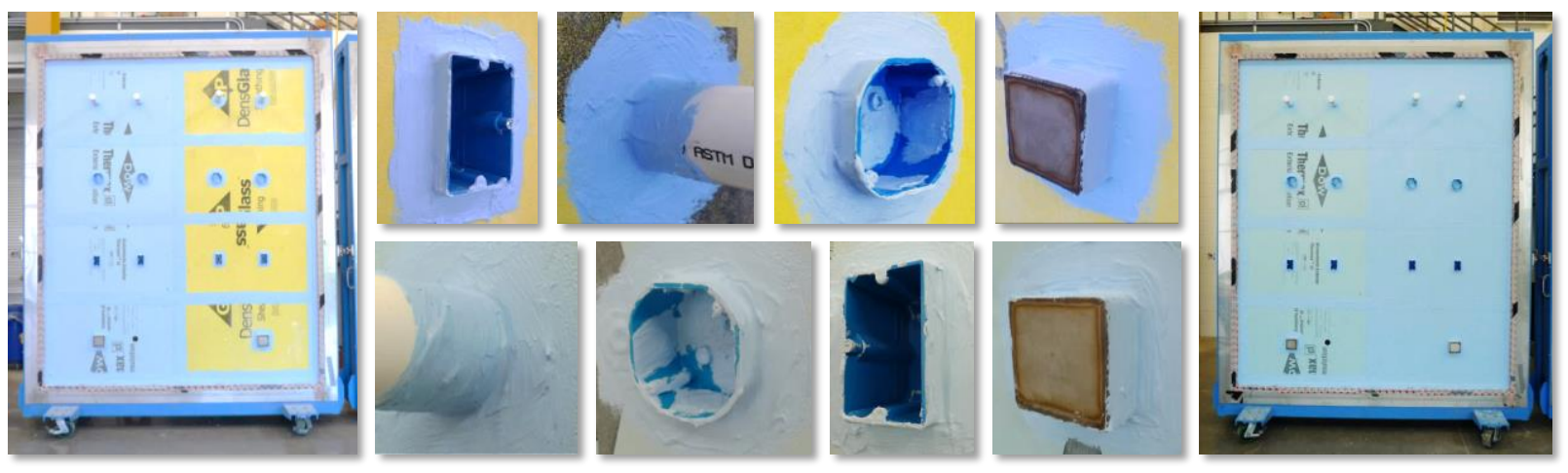

Figure 12. Test wall with THERMAX (ci) and DensGlass as the exterior sheathing. All the gaps around penetrations were about $1 / 4$ in. wide; thus, LIQUIDARMOR CM was installed without a supporting material.

The fourth test wall (Figure 13) was used to conduct a side-by-side comparison of LIQUIDARMOR CM and tape over $1 \mathrm{in.}$ thick THERMAX XARMOR, which is a foil-faced polyisocyanurate board. Gaps were $1 / 8$ in. wide between boards, $1 / 4$ in. wide around penetrations, and $1 / 2$ in. wide around the plywood window. Only the gaps around the windows had one-component spray foam as a supporting material for LIQUIDARMOR CM. Covers were made for the DensGlass and the THERMAX XARMOR walls so that their air leakage rates could be measured independently. 


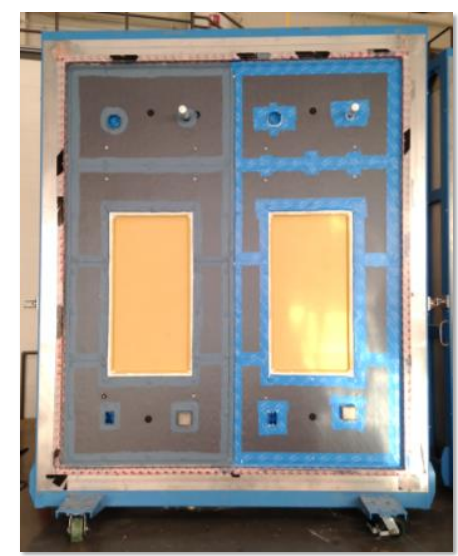

Figure 13. Test wall used to conduct a side-by-side evaluation of LIQUIDARMOR CM and tape.

The four walls had air leakage rates that met the requirements of the 2015 International Energy Conservation code for air barrier assemblies; that is, airflow measurements were less than $0.04 \mathrm{cfm} / \mathrm{ft}^{2}$ at $1.57 \mathrm{psf}$ after the walls were aged through pressure and temperature cycles. The effects of temperature on the air leakage rate were not observed, because measurements gathered before and after the walls were conditioned under hot and cold temperatures, according to the ASTM E1424 test standard, showed an air leakage rate lower than the chamber's minimum calibrated airflow rate of $1.4 \mathrm{cfm}$ or $0.02 \mathrm{cfm} / \mathrm{ft}^{2}$. ORNL provided Dow with recommendations on how to improve the installation of LIQUIDARMOR CM.

\subsubsection{M 3015 and $3015 \mathrm{VP}$}

Three walls with the $3 \mathrm{M}$ products were tested. The first wall consisted of $3 \mathrm{M} 3015$ over $5 / 8$ in. thick DensGlass (Figure 14). In the second wall, 3M 3015 was installed over $1 / 2$ in. thick Durock cement board, which was used as a surrogate for concrete (Figure 15A). The third wall had the 3M 3015VP membrane over $5 / 8$ in. thick DensGlass (Figure 15B).
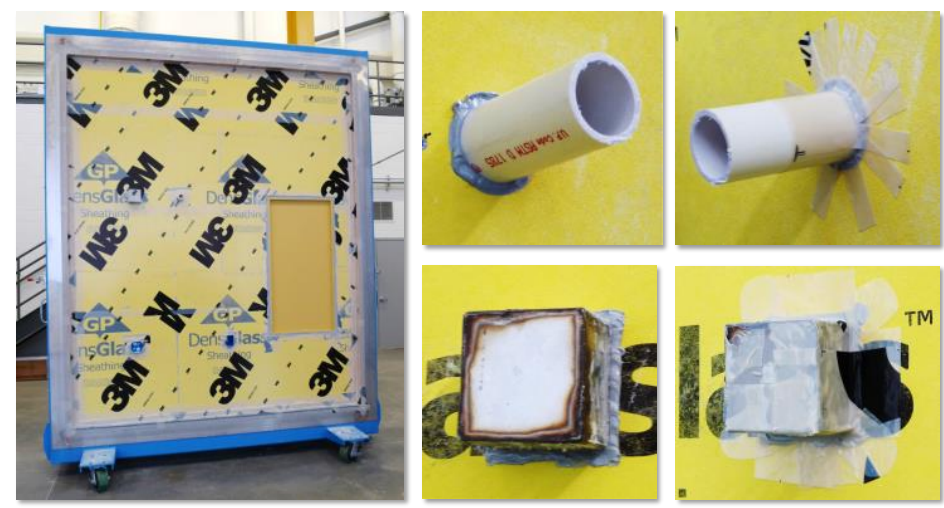

Figure 14. Test wall with $5 / 8$ in. thick DensGlass as the exterior sheathing and $3 \mathrm{M} 3015$ as the air, water, and vapor barrier. 

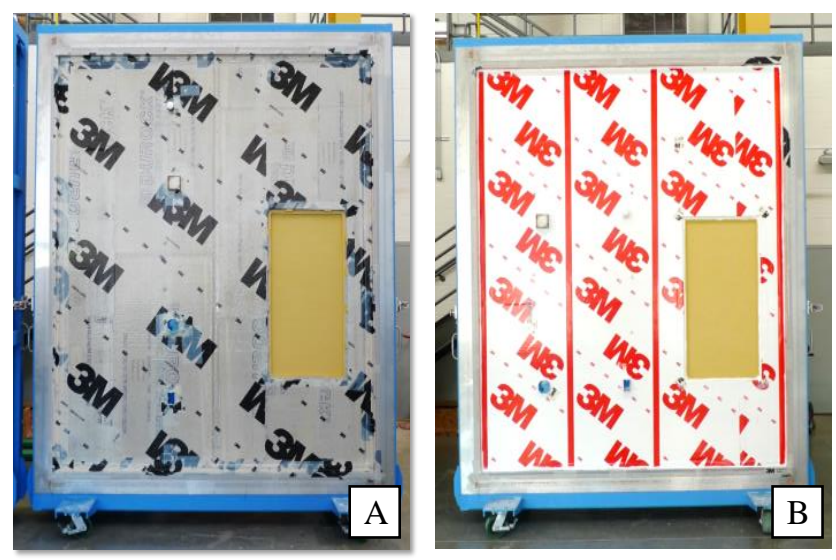

Figure 15. (A) Test wall with $1 / 2$ in. thick Durock as the exterior sheathing and $3 \mathrm{M} 3015$ as the air, water and vapor barrier. (B) Test wall with $1 / 2$ in. thick DensGlass and 3M 3015VP as the air and water barrier.

The three walls had air leakage rates that were less than $0.04 \mathrm{cfm} / \mathrm{ft}^{2}$ at $1.57 \mathrm{psf}$ after aging through pressure and temperature cycles. The effects of temperature on the air leakage rate were not observed because measurements gathered before and after the walls were conditioned under hot and cold temperatures, according to the ASTM E1424 test standard, showed an air leakage rate lower than the chamber's minimum calibrated airflow rate of $1.4 \mathrm{cfm}$ or $0.02 \mathrm{cfm} / \mathrm{ft}^{2}$. ORNL provided $3 \mathrm{M}$ with recommendations on how to improve installation of its self-adhered membranes.

\section{DEMONSTRATION BUILDINGS}

The demonstration buildings were to be located in China to facilitate the introduction of the Dow and 3M air sealing technologies, given that air barrier materials are not typically specified in China. The Chinese Ministry of Housing and Urban-Rural Development organized a meeting in Wuhan in November 2013 at which US researchers presented their technologies to developers who had projects scheduled to break ground in 2014 and 2015. ORNL initiated discussions with several of these developers on potential collaborations. Additionally, ORNL, Dow, and 3M pursued potential demonstration projects led by the P+ Design Group and the Shanghai Municipal State-Owned Assets Supervision and Administration Commission (SSASAC).

\subsection{METHODOLOGY}

Two possible approaches were to be pursued in the demonstration buildings to estimate the improvements in airtightness and/or reductions in energy use.

1. After completion of the building, conduct a blower door test according to ASTM E779, Standard Test Method for Determining Air Leakage Rate by Fan Pressurization. The measured leakage rate would be used in EnergyPlus models generated following the architectural drawings. Simulations would be run to estimate potential energy savings by using blower door data and leakage rates from the literature on buildings without air barriers.

2. Measure leakage rates through the interfaces between windows and the opaque wall using a modified version of ASTM E378, Standard Test Method for Field Measurement of Air Leakage Through Installed Exterior Windows and Doors. The test would be conducted on windows installed using the Dow and $3 \mathrm{M}$ air sealing technologies, and windows that followed typical installation practices in China would serve as baselines. 


\subsection{PURSUED SITES AND RESULTS}

\subsubsection{China Academy of Building Research, Beijing}

The China Academy of Building Research (CABR) four-story building was designed as a nearly-zero energy building (Figure 16). Technologies allowing for the attainment of this goal include a groundsource heat pump, solar panels, and vacuum insulated panels. ORNL, Dow, and 3M became aware of this project when the cladding was being installed; consequently, the air-sealing products could be installed only as flashing around window rough openings. Figure 17 illustrates how rough openings are typically prepared with a cementitious material before the window is installed. Figures 18 and 19 show how the cementitious material was protected against water with LIQUIDARMOR CM and 3M 3015, respectively.
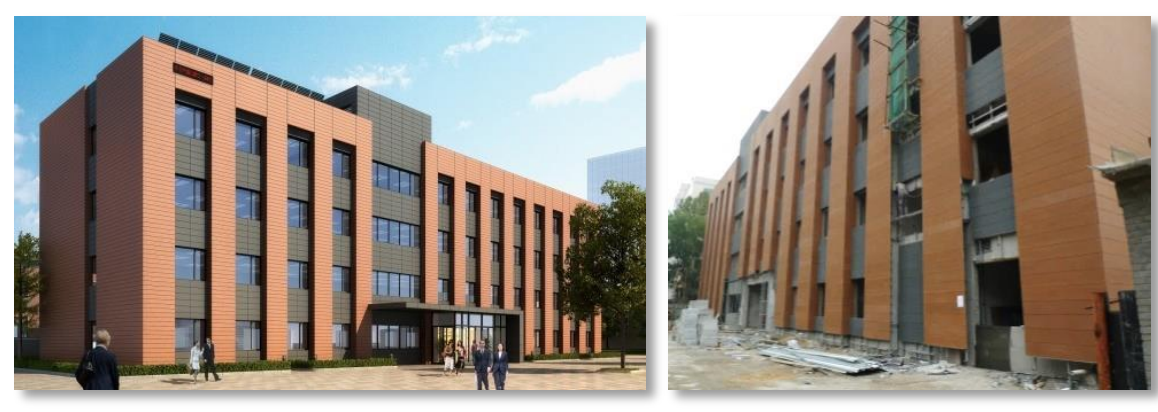

Figure 16. Nearly-zero energy building designed and developed by the China Academy of Building Research in Beijing.
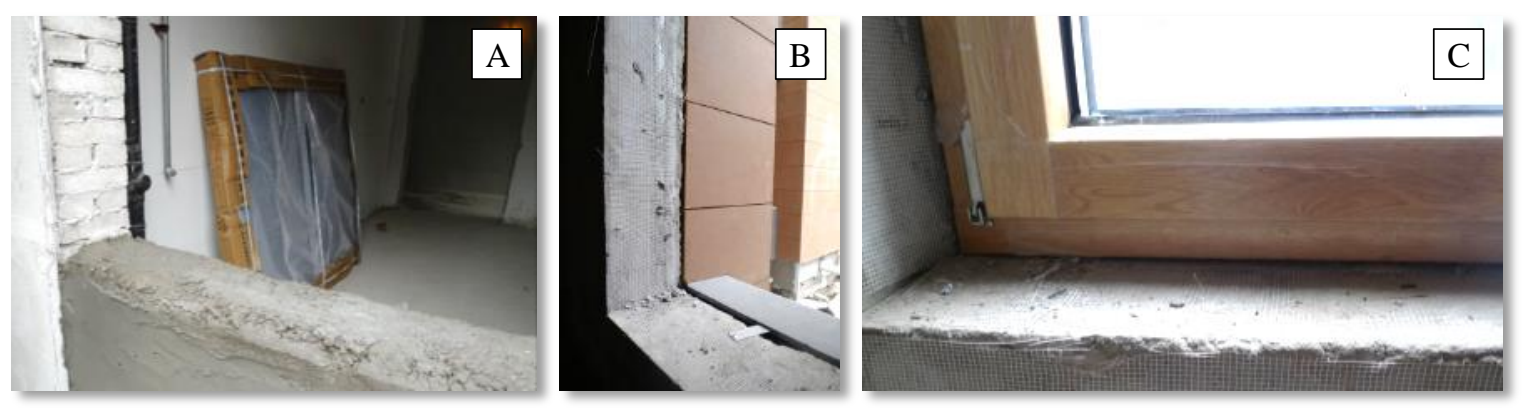

Figure 17. Typical window installation in China. (A and B) A cementitious material is applied over concrete rough opening. (C) Window is placed directly over the cementitious material. Gap between window and rough opening is filled with a sealant.

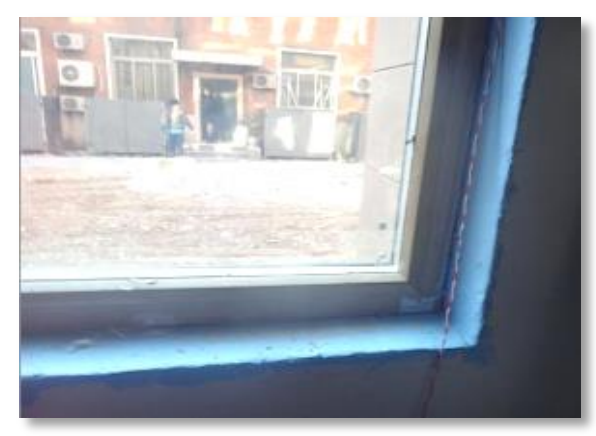

Figure 18. Concrete rough opening flashed with LIQUIDARMOR CM. 


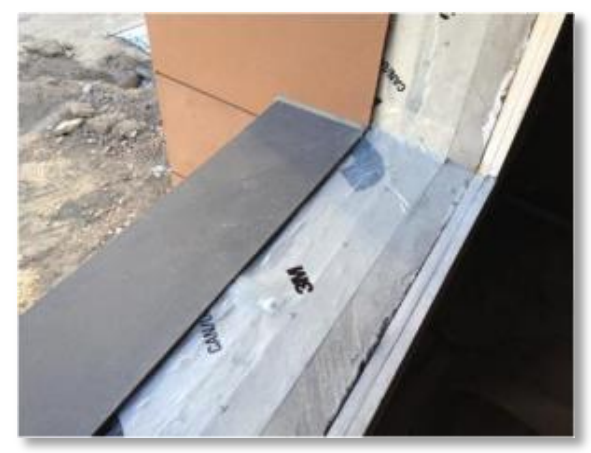

Figure 19. Concrete rough opening flashed with 3M 3015.

CABR followed a modified version of the ASTM E378 test standard to measure the air leakage rate through the gap around a window that was installed following typical practices, and around a window installed using LIQUIDARMOR CM and 3M 3015 as the flashing material. The CABR results indicate that the gap around the window installed with LIQUIDARMOR CM had a leakage rate $17 \%$ lower than the gap around the baseline window; this improvement was likely because the sealant used to fill the gap between the window and the rough opening adhered better to LIQUIDARMOR CM than to the cementitious material. Data were not gathered from the window with the $3 \mathrm{M}$ product because of problems with the window unit.

\subsubsection{Singyes Solar, Zhuhai}

The technologies considered by the developer of the Singyes Solar building (Figure 20) during the design phase of the project included building-integrated photovoltaics, natural ventilation, high-performance glass (solar heat gain coefficient $<0.3$, visible transmittance $>0.5$ ), and a building energy management system. The design also called for exterior mineral wool insulation covered with aluminum panels (Figure 21). Singyes contacted ORNL to determine if LIQUIDARMOR CM and/or 3M 3015 could be used to protect the insulation in lieu of the aluminum panels, because this substitution could lead to significant savings. ORNL, Dow, and $3 \mathrm{M}$ determined that this was not a good application for LIQUIDARMOR CM and 3M 3015 because the sealing technologies would probably not adhere properly to the fibrous surface of the mineral wool.

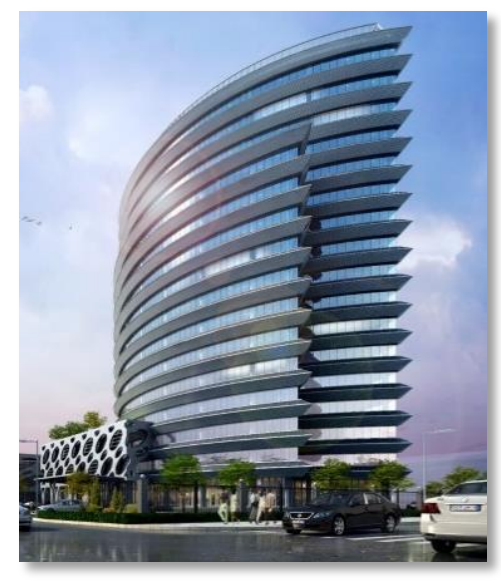

Figure 20. Singyes building in Zuhai. 


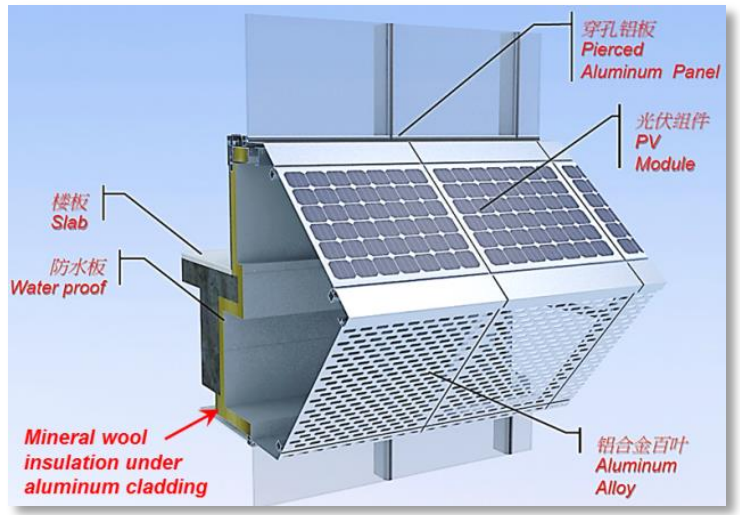

Figure 21. Cladding layout that shows building integrated photovoltaics, and the mineral wool insulation that was cladded with aluminum panels.

\subsubsection{Kelong Insulation, Jilin}

The Kelong Insulation building (Figure 22) was to be located in Jilin, an area in China with severe cold weather, e.g., average winter temperatures of $0^{\circ} \mathrm{F}$. This site would have been ideal for research on air leakage because infiltration is more detrimental in cold climates, given the high indoor-to-outdoor temperature differential. ORNL received drawings from the Kelong design team and multiple emails were exchanged. However, the project was significantly delayed and probably has been canceled.

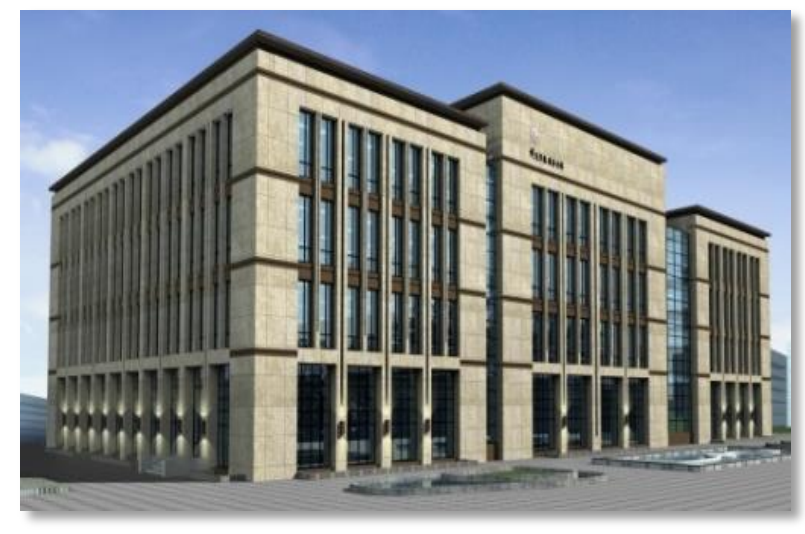

Figure 22. Proposed Kelong Insulation building in Jilin.

\subsubsection{Rixin Technologies, Wuhan}

Rixin Technologies planned to develop a series of residential buildings in Wuhan (Figure 23). This project would have been ideal for side-by-side comparisons of buildings that followed typical constructions practice with those that incorporated LIQUIDARMOR CM and/or 3M 3015. Unfortunately, the project was significantly delayed and likely canceled. 


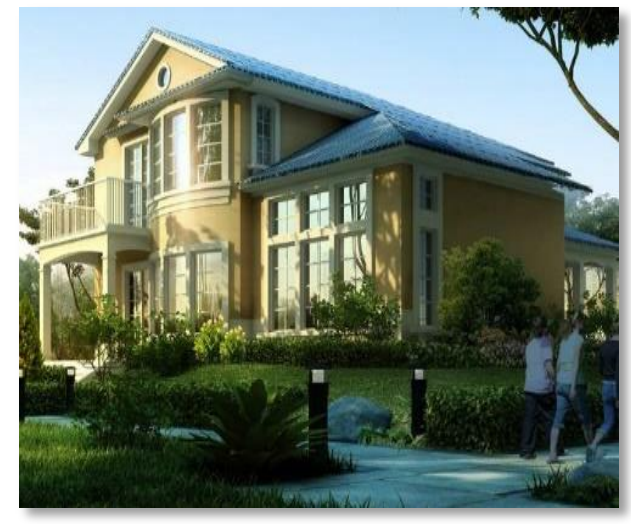

Figure 23. Proposed residence that was part of the development lead by Rixin Technologies in Wuhan.

\subsubsection{P+ Demonstration Building, Wujin}

The P+ Design Group is a collaborative of architects, engineers, and industry partners from the US, China, and the United Kingdom. P+ planned to develop a building in Wujin to demonstrate and educate the public on the latest energy-efficient technologies (Figure 24). ORNL held several discussions with P+, and representatives from Dow China visited the construction site. Unfortunately, the general contractor decided not to use LIQUIDARMOR CM because of the tight construction schedule.

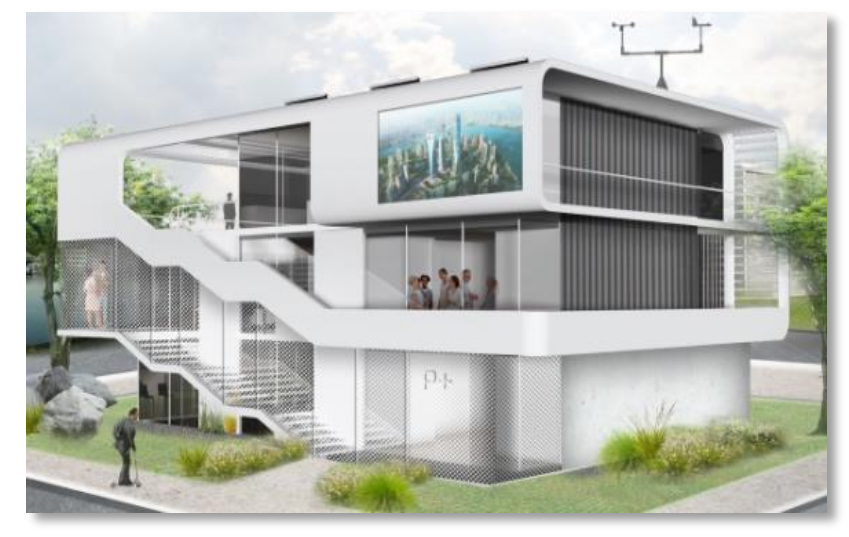

Figure 24. P+ Demonstration building in Wujin.

\subsubsection{Shanghai Municipal State-Owned Assets Supervision and Administration Commission}

SSASAC owns an old industrial building in Shanghai that it plans to renovate into a multi-purpose building (Figure 25). Dow-China and 3M-China visited the site and discussed with the design team whether their technologies could be used as part of the renovation of the building envelope. ORNL also visited the site in the fall of 2015; during this visit, the developer mentioned that the projected was postponed until 2016. 

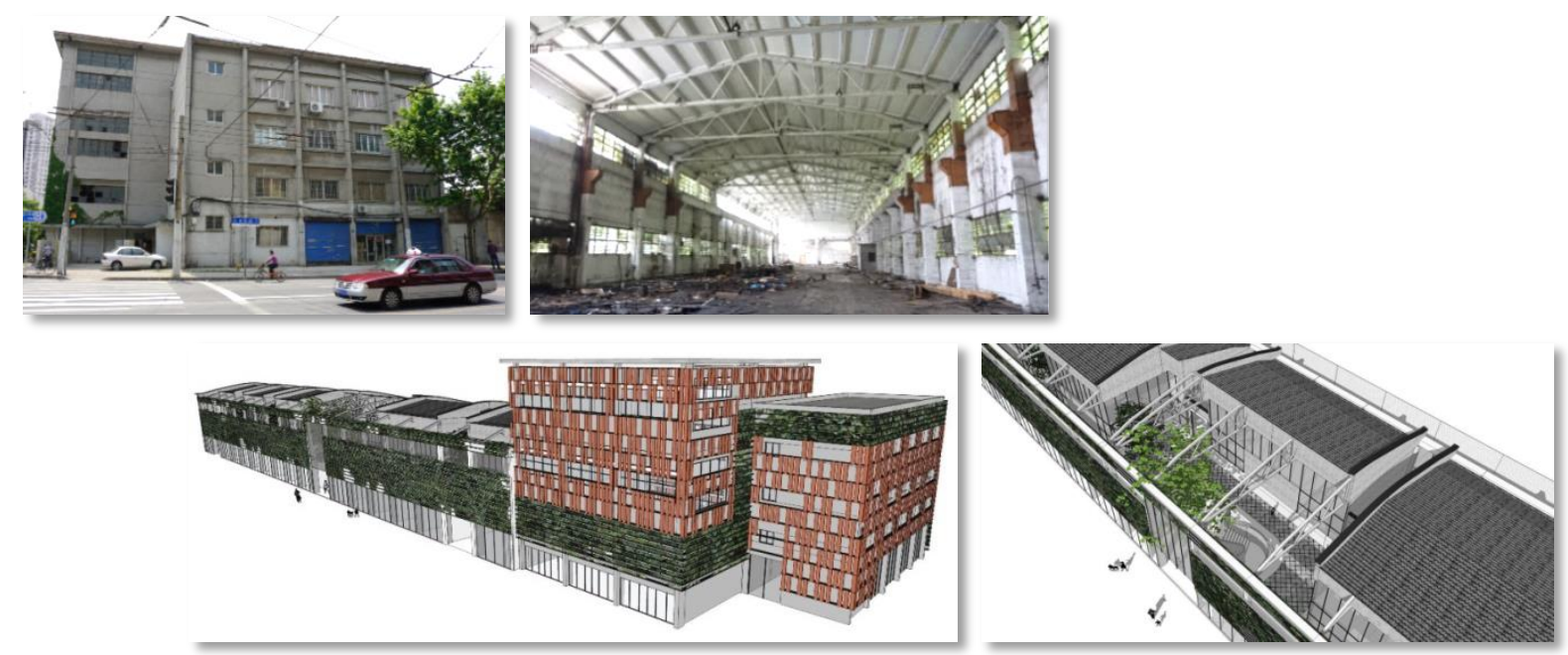

Figure 25. Industrial building in Shanghai (top) that will be renovated into retail and living quarters (bottom).

\section{CONCLUSION}

During this project, Dow and 3M successfully developed and launched new air-sealing technologies in the United States. In 2014 Dow introduced the only spray-applied liquid flashing, LIQUIDARMOR, which has won several awards. 3M launched two primer-less self-adhered membranes, 3015 and 3015VP. ORNL successfully validated the performance of each of these technologies through large-scale laboratory tests as a component of or as the main air barrier material in an air barrier system.

ORNL, Dow, and 3M attempted to demonstrate the newly developed technologies in six buildings in China. The team was able to install them only at a building owned by the CABR. The results suggest that the newly developed technologies could improve construction practices in China, because LIQUIDARMOR CM decreased infiltration rates by $17 \%$ around a window compared with traditional installation methods. Tests were not conducted with the $3 \mathrm{M}$ product because of difficulties with the installed window unit. 